\title{
Responses of the Transmembrane Potential Coupled to the ATP-evoked Catecholamine Release in Isolated Chromaffin Granules
}

\author{
Masaharu OgAwa and Akira InOuYe \\ Department of Physiology, Kyoto University, \\ School of Medicine, Kyoto, 606 Japan
}

\begin{abstract}
Using suspensions of chromaffin granules isolated from bovine adreno-medullae, the effects of $\mathrm{Mg}^{2+}$. ATP on membrane potential and catecholamine release across membranes of granules were investigated. The release of catecholamine was monitored by the measurement of changes in endogenous fluorescence of the amines, while the fluorometric method with $3,3^{\prime}$-dipropylthiadicarbocyanine iodide (diS- $\mathrm{C}_{3}-(5)$ ) was applied to the measurement of membrane potential changes. The catecholamine release brought about by $\mathrm{Mg}^{2+}$. ATP was found to obey Michaelis-Menten kinetics with $K_{\mathrm{m}}$-value for $\mathrm{Mg}^{2+}$ of about $0.15 \mathrm{mM}$ and to be inhibited by dicyclohexylcarbodiimide (DCCD), an inhibitor of membrane-bound $\mathrm{H}^{+}$-ATPase. Concomitantly with such an amine release, depolarization of the granule membrane was observed to occur. The magnitude of this depolarization closely paralleled with the rate of the amine release and followed a saturation kinetics of Michaelis-Menten type with $K_{\mathrm{m}}$ for $\mathrm{Mg}^{2+}$ of $0.21 \mathrm{~mm}$ and for ATP of $0.22 \mathrm{mM}$. Moreover, such a depolarization was competitively suppressed by DCCD. Based on these results, the role of the transmembrane potential change of granules in the catecholamine release was discussed.
\end{abstract}

Recently there appeared a number of reports which deal with regulatory role of membrane-bound ATPase in release from and uptake into adrenomedullar chromaffin granules of catecholamines. Radda and his colleagues (BASHFORD et al., 1976; CASEY et al., 1977) have found that the elements of a chemiosmotic system are present in chromaffin granules, and proposed a mechanism that catecholamine transport is coupled to the activity of membrane-bound proton pump. Experiments with some ionophores and uncouplers also showed that electroneutral $\mathrm{H}^{+}$influx and $\mathrm{K}^{+}$efflux in chromaffin granules occurred concomitantly with catecholamine release (JOHNSON and SCARPA, 1976a, b). In submitochondrial particles, chloroplasts and some bacteria, membrane-bound proton-trans-

Received for publication February 5, 1979

小川正晴, 井上 章 
locating ATPase has been known to regulate $\mathrm{H}^{+}-\mathrm{K}^{+}$exchange transport (RACKER, 1976). It seems quite natural, therefore, to assume that it is also the case in the chromaffin granules and the amine release is regulated by the $\mathrm{H}^{+}$-ATPase activity through the ion exchange transport. But still remains unsolved the question how to couple both processes.

In order to throw light upon this problem, responses of the membrane potential of the isolated granules to $\mathrm{Mg}^{2+}$. ATP were fluorometrically studied with a cyanine dye diS- $\mathrm{C}_{3}-(5)$. The ion exchange transport coupled with the amine release as a whole might be electroneutral as reported by JOHNSON and SCARPA (1976a, b); still remains a possibility of occurrence of a transient change in the transmembrane potential. Indeed, we found that the granules responded to ATP-induced amine release with depolarization. The present paper describes such an ATP-evoked depolarization of the isolated granules in relation to their rate of the amine release.

\section{MATERIALS AND METHODS}

Chromaffin granule preparation. The granules were prepared essentially as described by HofFman et al. (1976). Bovine adrenal glands were obtained at a slaughter house, placed on ice, and delivered to the laboratory within $1 \mathrm{hr}$. Four to six glands were immediately subjected to preparation in the cold. After cortices were removed, the isolated medullae were combined, cut into pieces and washed carefully with ice-cold unbuffered $0.3 \mathrm{~m}$ sucrose. The tissue pieces were placed in about $10 \mathrm{~mol}$ of same solution, blended for $5 \mathrm{sec}$ in a Waring Blender and then homogenized in a Potter-Elvehjem homogenizer. The homogenate was centrifuged at $500 \mathrm{~g}$ for $10 \mathrm{~min}$. The supernatant was carefully sucked off with a siliconized glass pipette without disturbing the sediments and centrifuged at $20,000 \mathrm{~g}$ for $30 \mathrm{~min}$ to a chromaffin granule pellet. The supernatant was gently sucked off with a Pasteur pipette. The upper layer of the pellet, "fluffy layer," containing mitochondria, was removed by careful washing with $5 \mathrm{ml}$ of $0.3 \mathrm{M}$ sucrose. The remaining part of the pellet was dispersed in $0.3 \mathrm{M}$ sucrose by repeated (20-30 times) pipetting with a wide bore pipette ( $1 \mathrm{~mm}$ in diameter), and centrifuged at $10,000 \mathrm{~g}$ for $30 \mathrm{~min}$. The supernatant was gently sucked off with a Pasteur pipette and the upper layer of the pellet was again removed by gentle swirling with $5 \mathrm{ml}$ of $0.3 \mathrm{M}$ sucrose. The pellet was resuspended in $0.3 \mathrm{M}$ sucrose by pipetting, as described above, and centrifuged at $7,000 \mathrm{~g}$ for $30 \mathrm{~min}$. The resulting supernatant was once again gently sucked off with a pipette and the centrifuge tube was inverted for no more than $2 \mathrm{sec}$. The final pellet thus obtained was resuspended in $0.3 \mathrm{~m}$ sucrose to have a protein concentration of $4-6 \mathrm{mg} / \mathrm{ml}$. All these procedures were carried out at $4^{\circ} \mathrm{C}$. Chromaffin granules thus prepared usually contained $0.4-0.6 \mathrm{mg}$ adrenaline/mg of protein. The granule sample was kept ice-cold, and used up within 
$60 \mathrm{hr}$ after preparation.

Fluorescence measurements. I. Fluorescence of $d i S-C_{3}-(5)$ : The fluorescent dye, 3,3'-dipropylthiadicarbocyanine iodide, diS- $\mathrm{C}_{3}-(5)$, was employed in this study. The dye was added to a known volume of solution with an adjustable pipette, the final concentration of dye was always $5.0 \mu \mathrm{g}$ per $3.0 \mathrm{ml}$ of medium. Fluorescence measurements were performed using a spectrofluorometer (Shimadzu, Type RF502) equipped with a Hamamatsu R-446 photomultiplier tube. A 10 $\mathrm{mm}$ quartz cuvette was used. The medium in the cuvette was stirred with a small magnetically driven glass flea. The temperature of medium was usually controlled at $35^{\circ} \mathrm{C}$ by circulating water through the cuvette holder.

II. Fluorescence of catecholamine: Fluorescence of endogenous catecholamine of chromaffin granule was measured with the same spectrofluorometer with excitation at $280 \mathrm{~nm}$ and emission at $320 \mathrm{~nm}$ (STEFFEN et al., 1974; JOHNSON and ScARPA, 1976b).

Measurements of catecholamines. Catecholamines were measured by two methods. For quantitative measurements of released catecholamine, granules were spun down and adrenaline was assayed by the fluorimetric trihydroxylindol method (ANTON and SAYRE, 1962), without an alumina chromatography. For kinetic measurements of catecholamine release, the endogenous fluorescence of the catecholamines was measured with the spectrofluorometer. This method was recently developed by STEFFEN et al. (1974) and JOHNSON and SCARPA (1976b) for catecholamine release and uptake in chromaffin granules. In this experiment, granules were added to a cuvette containing solution and the fluorescence increase was measured.

Solutions and drugs. When chromaffin granules were suspended in saline media, they behaved as an osmometer, obeying Boyle-van't Hoff's law and swelling in the media of less than 350 mOsm brought about release of catecholamines (JOHNSON and SCARPA, 1976b). Osmolarity of incubation media used in the present study was, therefore, adjusted around $370 \mathrm{mOsm}$ (360-380 mOsm), which was monitored with an Advance Osmometer model 3L (Advance Instruments, Inc.). The $\mathrm{pH}$ was adjusted at 6.5 with $40 \mathrm{~mm}$ HEPES.

The fluorescent dye for potential measurement, 3,3'-dipropylthiadicarbocyanine iodide (diS- $\mathrm{C}_{3}-(5)$ ) was obtained from Nippon Kanko-Shikiso Kenkyusho, Ltd., Okayama, Japan. Valinomycin, gramicidin D, ATP and other nucleotides were obtained from Sigma. X537A was a generous gift of Hoffman-La Roche, Nutley, N. J.. $N, N^{\prime}$-dicyclohexylcarbodiimide (DCCD), N-2-hydroxyethylpiperaxine- $N^{\prime}$-2-ethanesulfonic acid (HEPES) and other chemicals were of reagent grade. All the reagents were used without further purification.

Granules concentration. Concentrations of chromaffin granules in a reaction medium were expressed as $\mu \mathrm{g}$ of protein per $\mathrm{ml}$ of medium. Protein was assayed with the method of LOWRY et al. (1951), using bovine serum albumin as a standard. Before assay, protein was precipitated with $5 \%(\mathrm{w} / \mathrm{v})$ trichlo- 
roacetic acid to eliminate interference due to cross-reaction of catecholamines.

\section{RESULTS}

\section{Dye fluorescence and estimation of transmembrane potential}

On adding small amount of granules, the intensity of fluorescence of diS$\mathrm{C}_{3}-(5)$ dissolved in $\mathrm{NaCl}$ or choline $\mathrm{Cl}$ media attained a constant level within a few minutes. When the dye concentration was fixed (usually $5 \mu \mathrm{g}$ per $3 \mathrm{ml}$ ), this steady level of fluorescence was same for both media, but strongly depended upon $\mathrm{K}^{+}$concentrations (Figs. 1 and 3). Moreover, addition of valinomycin, an ionophore known to induce a marked increase in $\mathrm{K}^{+}$permeability in chromaffin granules (Kitabgi and Perlman, 1975), brought about further decreases in the fluorescence; the lower the $\mathrm{K}^{+}$concentration the greater such a decrease in fluorescence intensity $(F)$. In the presence of ionophore, $F$ varied log-linearly with external $\mathrm{K}^{+}$concentration, $(\mathrm{K})$ o (Fig. 1). The relationship between $F$ and $\log (\mathrm{K})_{\mathrm{o}}$ in the presence of gramicidin, an ionophore which makes biological and artificial membrane permeable to $\mathrm{K}^{+}$and $\mathrm{Na}^{+}$but not to choline ${ }^{+}$, was also found to be linear over most of the range studied in choline ${ }^{+}-\mathrm{K}^{+}$media (Fig. 1). Such results were quite similar with those obtained on a number of different cell preparations (for review see COHEN and SALzBerg, 1978), indicating that increases

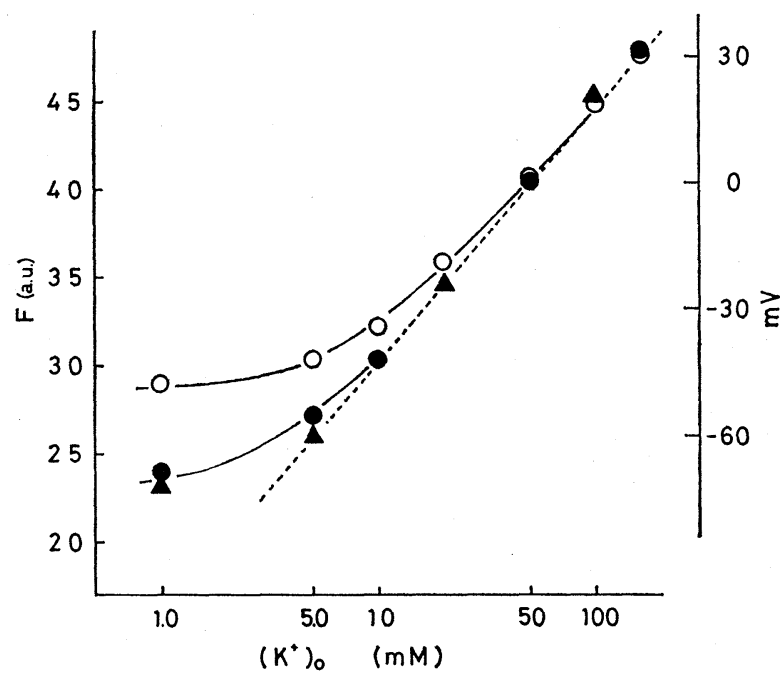

Fig. 1. The influence of the extragranular potassium concentration on the steady level of fluorescence intensity of the dye diS- $\mathrm{C}_{3}-(5)$ in suspensions of intact bovine chromaffin granules $(19 \mu \mathrm{g}$ protein $/ \mathrm{ml})$ in the absence $(\mathrm{O})$ and presence of $1.0 \mu \mathrm{g} /$ $\mathrm{ml}$ gramicidin ( $(\bullet)$ or $0.2 \mu \mathrm{g} / \mathrm{ml}$ valinomycin ( $\Delta$ ). The media were made by substituting $160 \mathrm{mM} \mathrm{KCl}$ for a portion of $160 \mathrm{~mm}$ choline $\mathrm{Cl}$ solution to give the $\left(\mathrm{K}^{+}\right)_{\mathrm{o}}$ shown on the figure. 
in $F$ reflect depolarization of membrane potential.

Applying essentially the same procedure as that employed for other preparations, therefore, the magnitude of changes in the membrane potential was estimated from the fluorescence changes; assuming that the log-linear changes in $F$ with respect to $\left(\mathrm{K}^{+}\right)_{\mathrm{o}}$ in the presence of ionophores reflect the Nernst equation for the reversible $\mathrm{K}^{+}$electrode. Thus the broken lines in Figs. 1 and 3 were drawn to transform the fluorescence scale into the potential one. This procedure is sufficient to approximately estimate the potential change in $\mathrm{mV}$. It is necessary for estimating the absolute value of membrane potential to determine the fluorescence intensity at $0 \mathrm{mV}$. For this purpose, we tentatively used the $F$ measured on the suspension of lysed granules; the intact granules were suspended in hyposmotic media ( $20 \mathrm{~mm}$ HEPES of $\mathrm{pH} 6.5$ alone) to rupture granules and then the suspensions were brought to 380 mOsm by adding choline $\mathrm{Cl}$ solution. The value of $F$ obtained on this suspension was taken as that corresponding to the transmembrane potential of $0 \mathrm{mV}$. This approximation was supported by the observation that when gramicidin was added to the intact chromaffin

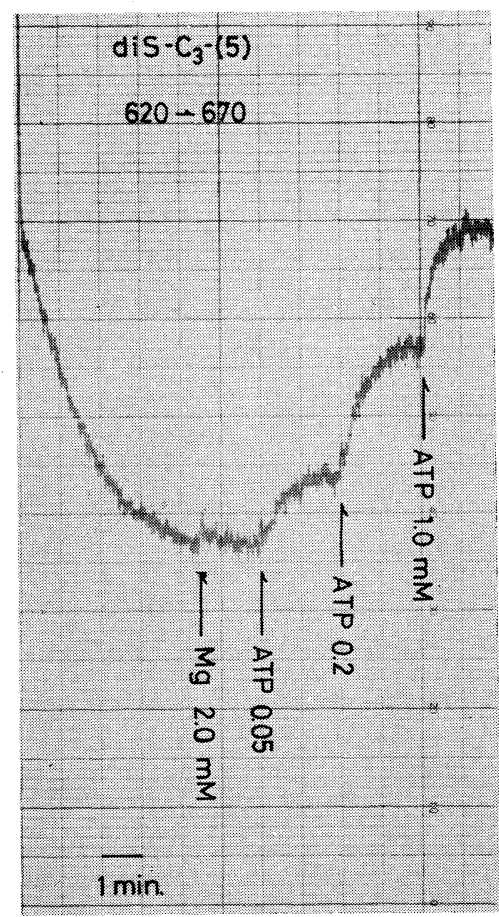

Fig. 2. Effect of $\mathrm{Mg}^{2+}$ and ATP on the fluorescence intensity of diS- $\mathrm{C}_{3}-(5)$ in suspensions of intact chromaffin granules $(25 \mu \mathrm{g}$ protein $/ \mathrm{ml})$. The medium was $160 \mathrm{~mm}$ $\mathrm{NaCl}$. At time marked with arrows, $\mathrm{Mg}^{2+}$ and ATP were added with an adjustable fine syringe to give the final concentration shown on the figure. 


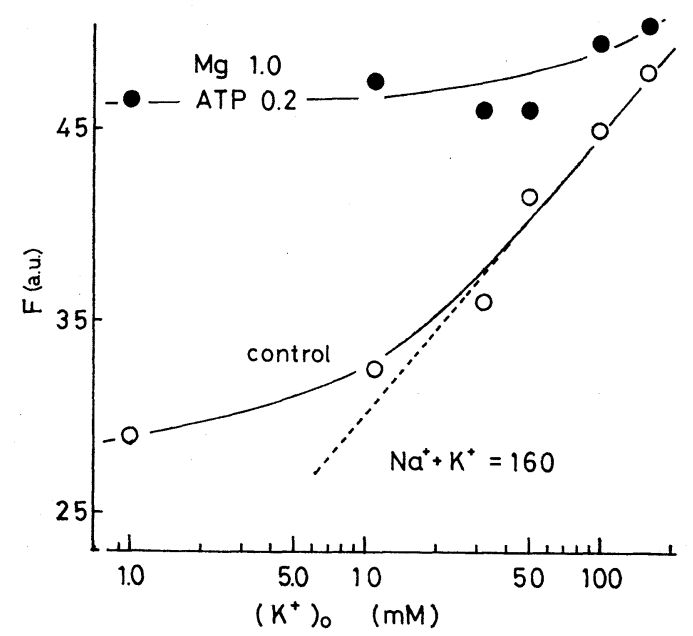

Fig. 3. Effect of $\left(\mathrm{K}^{+}\right)_{0}$ on the $\mathrm{Mg}^{2+} \cdot \mathrm{ATP}$-evoked fluorescence changes of $\mathrm{diS}^{-\mathrm{C}_{3}-(5)}$ in suspension of intact chromaffin granules $(16 \mu \mathrm{g}$ protein $/ \mathrm{ml})$. The media were made by substituting $160 \mathrm{mM} \mathrm{KCl}$ for a portion of $160 \mathrm{mM} \mathrm{NaCl}$ solution to give the $\left(\mathrm{K}^{+}\right)_{\mathrm{o}}$ shown on the figure.

granules in $\mathrm{Na}^{+}+\mathrm{K}^{+}$medium $F$ increased identical to the value obtained with lysed granules. Furthermore, the attained level of $F$ on addition of gramicidin was independent of $\mathrm{Na}^{+}$and $\mathrm{K}^{+}$concentrations of medium. These are the results to be expected if gramicidin makes chromaffin granule membrane indiscriminately permeable to $\mathrm{Na}^{+}$and $\mathrm{K}^{+}$and depolarizes granules to $0 \mathrm{mV}$ as shown with electroplax membranes (Podleski and Changeaux, 1969). With this method the membrane potential of granules was estimated to be around $-45 \mathrm{mV}$ (inside negative) in $1 \mathrm{~mm}\left(\mathrm{~K}^{+}\right)_{0}$, and $+15 \mathrm{mV}$ in $100 \mathrm{~mm}\left(\mathrm{~K}^{+}\right)_{\mathrm{o}}$ (Fig. 1).

\section{Membane depolarization evoked by $\mathrm{Mg} \cdot \mathrm{ATP}$}

In the presence of $\mathrm{Mg}^{2+}$, but not in its absence, ATP brought about increase in the fluorescence, namely depolarization (Fig. 2). As shown in Fig. 3 , the magnitude of depolarization strongly depended on $\left(\mathrm{K}^{+}\right)_{0}$; around $72 \mathrm{mV}$ in $1 \mathrm{~mm}\left(\mathrm{~K}^{+}\right)_{0}$ but about $20 \mathrm{mV}$ in $100 \mathrm{~mm}\left(\mathrm{~K}^{+}\right)_{0}$.

Nucleotides other than ATP, for instance AMP, cAMP and GTP were all without effect of such a remarkable depolarizing action. It might be said that $\mathrm{Mg}^{2+} \cdot$ ATP is specifically responsible for the depolarization observed here.

As shown in Fig. 4, the increment of fluorescence, $\Delta F$, (i.e. magnitude of depolarization) brought about by $\mathrm{Mg}^{2+}$. ATP in low $\mathrm{K}^{+}$media increased hyperbolically with increasing ATP and $\mathrm{Mg}^{2+}$ concentrations. Indeed, the double reciprocal plots, $1 / \Delta F$ vs. $1 /$ ATP or $1 / \mathrm{Mg}^{2+}$ were linear (Fig. 5) and the dissociation constants, $K_{\mathrm{m}}$, estimated therefrom, were 0.22 and $0.21 \mathrm{mM}$ for ATP and $\mathrm{Mg}^{2+}$, 


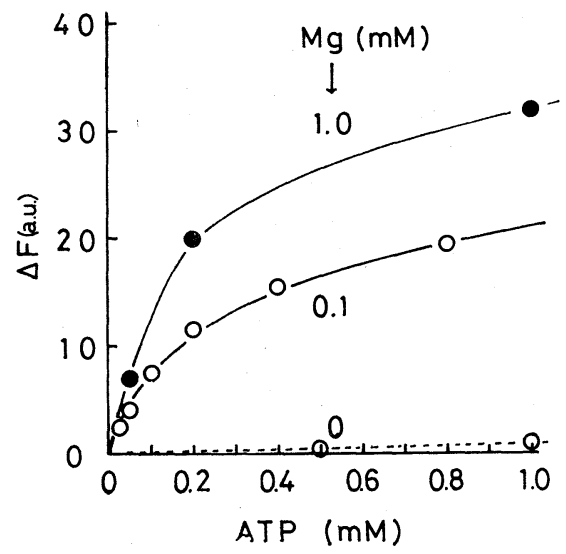

Fig. 4. Influence of ATP concentration on fluorescence change $(\Delta F)$ of $\operatorname{diS}_{-} \mathrm{C}_{3}-(5)$ in suspension of intact chromaffin granules $(25 \mu \mathrm{g}$ protein $/ \mathrm{ml})$. The media contained $160 \mathrm{~mm} \mathrm{NaCl}$ and $0.1 \mathrm{~mm}(0), 1.0 \mathrm{~mm}(\bullet)$ or $0 \mathrm{mM} \mathrm{Mg}^{2+}$ (dashed line).
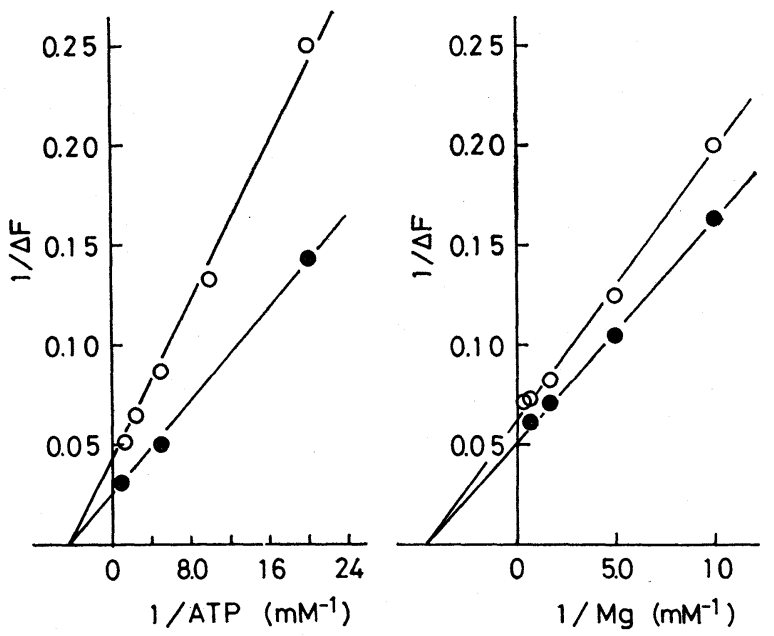

Fig. 5. Left: Double-reciprocal plots for fluorescence changes $(\Delta F)$ with ATP. Data are shown in Fig. 4. The media contained $0.1 \mathrm{~mm}(\mathrm{O})$ or $1.0 \mathrm{~mm} \mathrm{Mg}$ (๑). The intercept at the abscissa of the extrapolated lines gives the value of negative inverse of $K_{\mathrm{m}}$ for ATP. Right: Double-reciprocal plots for fluorescence changes with $\mathrm{Mg}^{2+}$. The media contained $160 \mathrm{~mm} \mathrm{NaCl}$ and $0.1 \mathrm{~mm}$ (O) or $0.2 \mathrm{~mm} \mathrm{ATP} \mathrm{( \bullet ).} \mathrm{The} \mathrm{intercept} \mathrm{at} \mathrm{the} \mathrm{abscissa} \mathrm{of} \mathrm{the} \mathrm{extrapolated} \mathrm{lines}$ gives the value of negative inverse of $K_{\mathrm{m}}$ for $\mathrm{Mg}^{2+}$. 
Table 1. Dependence of $\mathrm{Mg}^{2+} \cdot \mathrm{ATP}$-evoked depolarization on temperature.

\begin{tabular}{ccc}
\hline Temperature $\left({ }^{\circ} \mathrm{C}\right)$ & $\Delta \mathrm{F}(\mathrm{a} . \mathrm{u} .)^{*}$ & Depolarization $(\mathrm{mV})^{* *}$ \\
\hline 35 & 58 & 72 \\
25 & 48 & 59 \\
15 & 34 & 42 \\
10 & 20 & 25 \\
5 & 8 & 10 \\
\hline
\end{tabular}

The enhancement of fluorescence of dye upon the addition of $1.0 \mathrm{mM} \mathrm{Mg}^{2+}$ and $0.2 \mathrm{mM}$ ATP was measured at various temperature in suspensions of intact chromaffin granules $(25 \mu \mathrm{g}$ protein $/ \mathrm{ml}$ ). The media contained $160 \mathrm{~mm} \mathrm{NaCl}$.

* The scale of fluorescence change is given in Fig. 3.

** By assuming that the fluorescence change in 10 -fold increase in $\left(\mathrm{K}^{+}\right)_{0}$ under the presence of valinomycin corresponds to a potential change $2.3 \times R T / F$, the $\mathrm{Mg}^{2+} \cdot \mathrm{ATP}$-evoked fluorescence change is estimated in $\mathrm{mV}$. A result for $35^{\circ} \mathrm{C}$ is given in Fig. 3 .

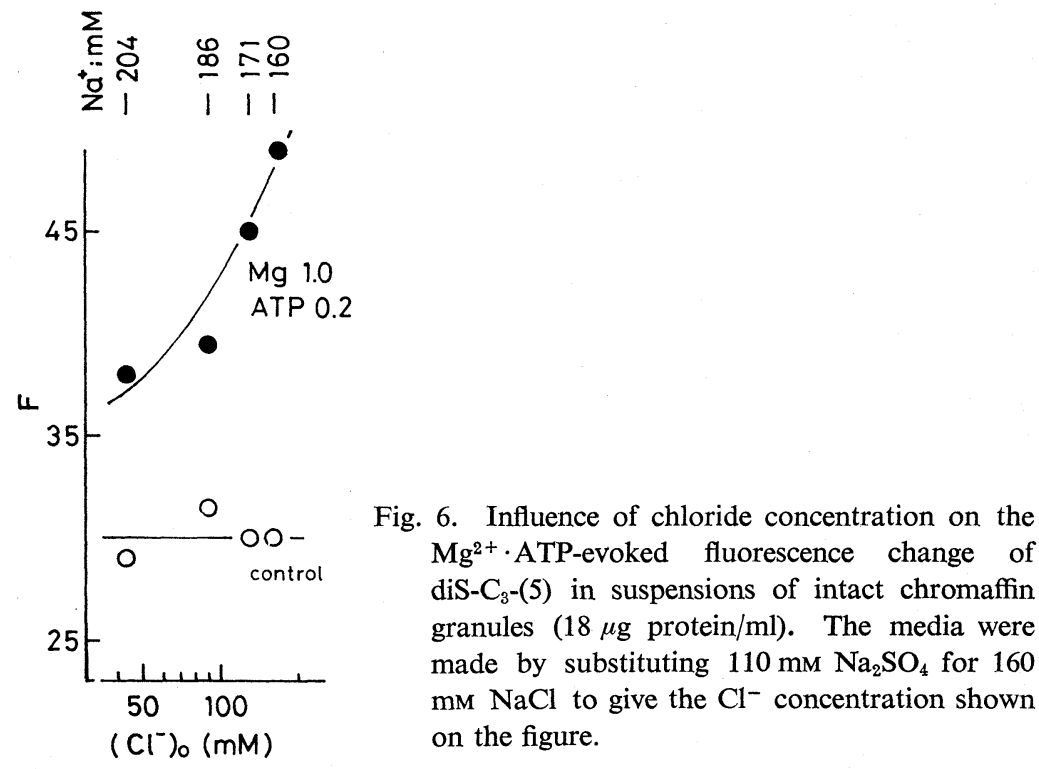

respectively. The values coincided well with those obtained from $\mathrm{Mg}^{2+} \cdot \mathrm{ATP}$ evoked release of catecholamine from chromaffin granules (HoFfman et al., 1976). Such a fact strongly points to a close correlation of the amine release with the membrane depolarization in granules. In fact, the present study proved, as described below, that this is the case. In this connection, it should be noticed in Fig. 5b that $1 / \Delta F-1 / \mathrm{Mg}^{2+}$ relation at high $\mathrm{Mg}^{2+}$ concentration shows deviation from linearity, which has, as described below in detail ( $c f$. Fig. 10), a close relation to inhibition of amine release by high $\mathrm{Mg}^{2+}$ (HoffMAN et al., 1976).

The magnitude of depolarization brought about by $\mathrm{Mg}^{2+} \cdot \mathrm{ATP}$ was dependent on temperature, but its dependency was found to be far more greater than 
that expected from the thermodynamic factor $R T / F$ (Table 1). This finding suggests participation of a carrier or carriers to ionic mechanisms of ATP-induced depolarization.

The effects of anions on the release of catecholamine from and the activity of ATPase in chromaffin granules were discussed by TAUGNER (1972) and CASEY et al. (1976). They found that replacement of $\mathrm{Cl}^{-}$with $\mathrm{SO}_{4}{ }^{2-}$ does not inhibit ATPase activity but does suppress the $\mathrm{Mg}^{2+}$. ATP-induced amine release. As shown in Fig. 6, the membrane potential in the absence of ATP remained unaltered despite varying external $\mathrm{Na}^{+}$and $\mathrm{Cl}^{-}$concentrations, where the osmolarity of medium remained constant, but the magnitude of $\mathrm{Mg}^{2+} \cdot \mathrm{ATP}$ evoked depolarization decreased with decreasing $\mathrm{Cl}^{-}$. Such a finding suggests that change of permeability or distribution of $\mathrm{Cl}^{-}$across the granule membrane contributes to $\mathrm{Mg}^{2+}$. ATP-evoked depolarization and amine release.

\section{Effect of DCCD on ATP-evoked depolarization}

Dicyclohexylcarbodiimide (DCCD) is known to covalently bind with membrane $\mathrm{H}^{+}$-ATPase, resulting in inhibition of active proton transport in submitochondrial particles and some bacteria (RACKER, 1976); furthermore it is also a potent inactivator of $\mathrm{Mg}^{2+}$-dependent ATPase in the chromaffin granule membrane (BASHFORD et al., 1976). This drug never affected the so-called resting potential of chromaffin granules, nor altered its depolarization response to high $\left(\mathrm{K}^{+}\right)_{\mathrm{o}}$, however, DCCD competitively inhibited the depolarization response to
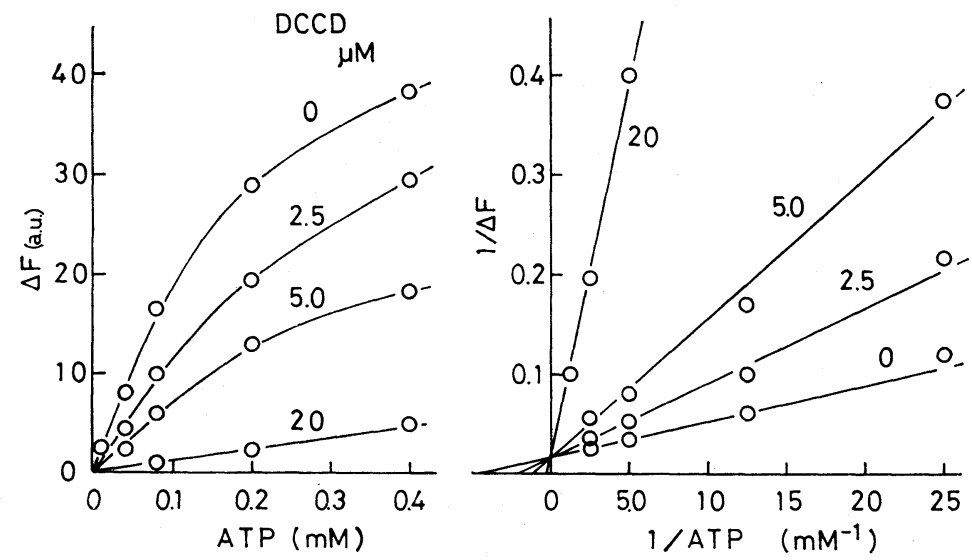

Fig. 7. Left: Effect of DCCD on the $\mathrm{Mg}^{2+} \cdot \mathrm{ATP}$-evoked fluorescence change of diS- $_{3}-(5)$ in suspensions of intact chromaffin granules $(21 \mu \mathrm{g}$ protein $/ \mathrm{ml})$. The media contained $160 \mathrm{~mm} \mathrm{NaCl}$ and the concentrations of DCCD indicated. The fluorescence changes of diS- $\mathrm{C}_{3}-(5)$ on addition of ATP were then measured. Right: Double-reciprocal plots for fluorescence changes $(\Delta F)$ with ATP under several concentrations of DCCD. Data are shown in left. 
$\mathrm{Mg}^{2+} \cdot$ ATP (Fig. 7). In contrast the addition of oligomycin, a potent inhibitor of $\mathrm{H}^{+}$-ATPase in mitochondria, had, unlike DCCD, no significant effect upon $\mathrm{Mg} \cdot$ ATP-evoked depolarization. This finding was consistent with those of BASHFORD et al. (1976), who found that oligomycin was without effect on the DCCD-sensitive ATPase activity in chromaffin granules. Thus it is very likely that ATP induces depolarization through interaction with DCCD-sensitive sites in membrane, most probably with a DCCD-sensitive $\mathrm{H}^{+}$-ATPase. These results correspond with those of CASEY et al. (1977), who observed active proton uptake which followed the addition of ATP in chromaffin granules was abolished by a mitochondrial uncoupler S-13.

\section{Changes in internal $\mathrm{K}^{+}$evoked by $\mathrm{Mg}^{2+} \cdot \mathrm{ATP}$}

JoHNSON and SCARPA $(1976 \mathrm{a}, \mathrm{b})$ found that $\mathrm{K}^{+}-\mathrm{H}^{+}$exchange across the membrane of chromaffin granules induced by the ionophore nigericin or by valinomycin and the uncoupler FCCP. It is conceivable that exchange of $\mathrm{H}^{+}$ with $\mathrm{K}^{+}$may be involved in generation of the depolarization response to $\mathrm{Mg}^{2+}$. ATP. To test such a possibility, we attempted to indirectly estimate changes in intragranular $\mathrm{K}^{+}$concentration by measuring the $\mathrm{K}^{+}$equilibrium potential before and after the onset of $\mathrm{Mg}^{2+} \cdot \mathrm{ATP}$-evoked depolarization response. For this purpose, we used valinomycin which produces highly selective increase in $\mathrm{K}^{+}$permeability in biological and artificial membranes, but which hardly affects the $\mathrm{H}^{+}$permeability in choline $\mathrm{Cl}$ media (JoHNSON and SCARPA, 1976a, b). As shown in Fig. 1, valinomycin induced hyperpolarization and the fluorescence of dye in its presence log-linearly varied for $\left(\mathrm{K}^{+}\right)_{0}$ of $10-100 \mathrm{mM}$, reflecting the $\mathrm{K}^{+}$equilibrium potential. Selecting an appropriate external $\mathrm{K}^{+}$concentra-

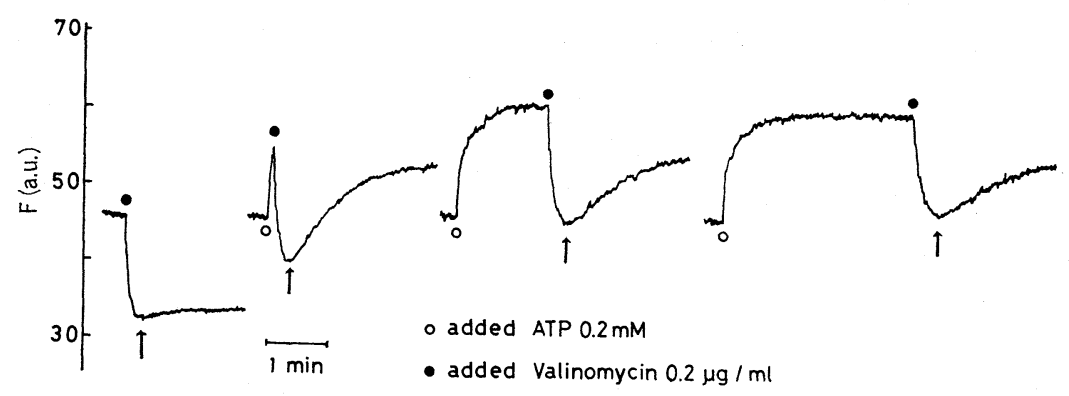

Fig. 8. Time course of the effects of valinomycin $(0.2 \mu \mathrm{g} / \mathrm{ml})$ on the $\mathrm{Mg}^{2+} \cdot \mathrm{ATP}-$ evoked fluorescence change of diS- $_{3}-(5)$ in suspensions of intact chromaffin granules $(17 \mu \mathrm{g}$ protein $/ \mathrm{ml})$. The media contained $160 \mathrm{~mm}$ choline $\mathrm{Cl}$ and $1.0 \mathrm{~mm}$ $\mathrm{MgCl}_{2}$. After the fluorescence attained a steady level, $0.2 \mathrm{mM}$ ATP was added to the medium $(0)$. Valinomycin was added at the time indicated $(\bullet)$. Note that the transient minimum fluorescence intensity (indicated by arrow) shifts upward as the ATP-evoked response proceeds. 
tion, therefore, changes in the fluorescence level in the presence of the ionophore reflects those in internal $\mathrm{K}^{+}$concentration, $\left(\mathrm{K}^{+}\right)_{\mathrm{i}}$. An example of such experiments is presented in Fig. 8. Addition of the ionophore brought about instantaneous decrease in the fluorescence (hyperpolarization) to a new level, corresponding to the $\mathrm{K}^{+}$equilibrium potential determined by the ratio $\left(\mathrm{K}^{+}\right)_{\mathrm{o}} /\left(\mathrm{K}^{+}\right)_{\mathrm{i}}$. After the onset of ATP-induced depolarization, a biphasic change in the fluorescence was induced by addition of valinomycin; a rapid decrease and a slow increase. The transient minimum level in fluorescence (indicated with arrows in the figure), corresponding to the $\mathrm{K}^{+}$-equilibrium potential, gradually increased as the ATPdepolarization response proceeded; the difference in the $\mathrm{K}^{+}$equilibrium potential between before and $3.5 \mathrm{~min}$ after the onset of ATP-depolarization was estimated to be about $60 \mathrm{mV}$ in choline $\mathrm{Cl}$ medium. The volume of chromaffin granules in suspension was so small that $\left(\mathrm{K}^{+}\right)_{0}$ can be safely regarded as constant. Thus the change of $\mathrm{K}^{+}$equilibrium potential of $60 \mathrm{mV}$ indicates $\left(\mathrm{K}^{+}\right)_{\mathrm{i}}$ to be reduced to about $1 / 10$ at $3.5 \mathrm{~min}$ after the onset of the ATP-depolarization response. While we did not estimate the volume changes of chromaffin granules, these should not affect the qualitative observation of intragranular $\mathrm{K}^{+}$change since 10 -fold increase in volume would be required to account for the observed decrease in $\left(\mathrm{K}^{+}\right)_{\mathrm{i}}$. Thus it might be concluded that $\mathrm{Mg}^{2+} \cdot \mathrm{ATP}$ brings about release of intragranular $\mathrm{K}^{+}$concomitantly with generation of membrane depolarization.

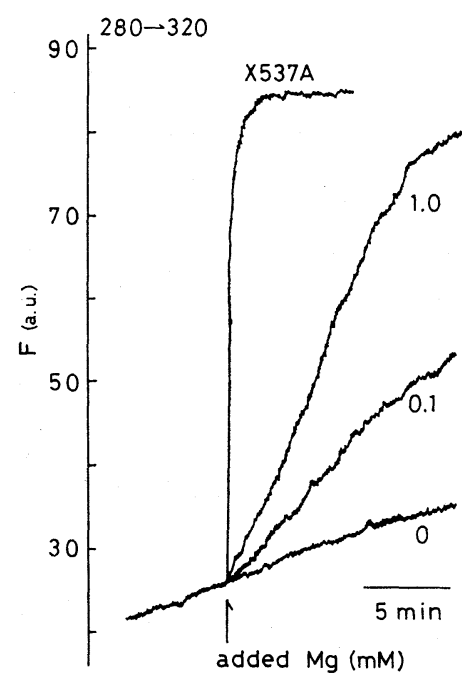

Fig. 9. Time course of the catecholamine release from intact chromaffin granules ( $25 \mu \mathrm{g}$ protein $/ \mathrm{ml}$ ) after addition of various concentrations of $\mathrm{Mg}^{2+}$. The media contained $160 \mathrm{~mm} \mathrm{NaCl}$ and $0.2 \mathrm{mM}$ ATP. Catecholamine release was directly monitored by measuring the fluorescence increase of endogenous amines (excited at $280 \mathrm{~nm}$ and emission at $320 \mathrm{~nm}$ ). 

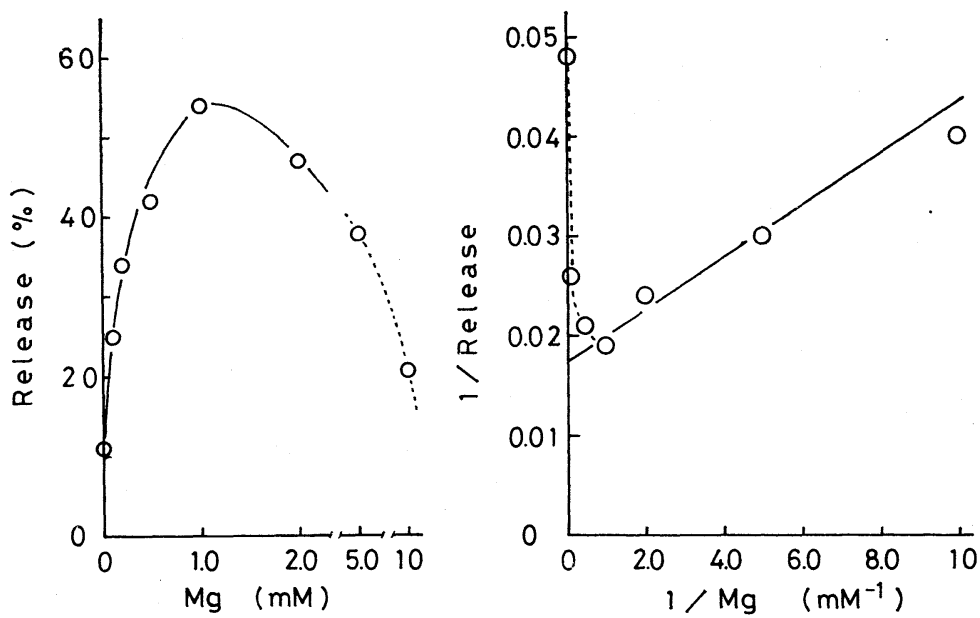

Fig. 10. Left: Effect of $\mathrm{Mg}^{2+}$ on catecholamine release from intact chromaffin granules (25 $\mu$ g protein $/ \mathrm{ml})$. Experimental conditions as in Fig. 9. By computing the fluorescence increase induced by X537A as full release of catecholamines from granules, per cent release of catecholamines was estimated with $\mathrm{Mg}^{2+}$ induced fluorescence enhancement for initial $6 \mathrm{~min}$. Right: Double-reciprocal plot for relative rate of catecholamine release with $\mathrm{Mg}^{2+}$. Data are shown in left.

\section{5. $\mathrm{Mg}^{2+} \cdot$ ATP-dependent catecholamine release}

Catecholamine release was directly followed up by monitoring the endogenous amine of suspended chromaffin granules by fluorescence measurement. To avoid disturbances due to absorption of light near $280 \mathrm{~nm}$ by ATP, this series of experiments was conducted in the presence of a fixed amount of ATP in the suspending media. Thus the amine release was evoked by adding $\mathrm{Mg}$ ion. An example of such experiments is illustrated in Fig. 9.

As already shown by JoHnSON and SCARPA (1974), an ionophore X537A produced very rapid efflux of whole catecholamine in the granules independently of whether or not ATP and/or $\mathrm{Mg}^{2+}$ are present. Furthermore, X537A induced full release of catecholamine in the presence of DCCD. Therefore, we always used such a catecholamine release brought about by X537A as the reference for estimating the rate of amine release evoked by $\mathrm{Mg}^{2+} \cdot \mathrm{ATP}$.

Compared to the X537A-induced amine release, $\mathrm{Mg}^{2+} \cdot \mathrm{ATP}$-dependent release was slow. The rate of release depended upon $\mathrm{Mg}^{2+}$ concentration but remained constant, at a fixed $\mathrm{Mg}^{2+}$ concentration, at least for initial 10 min, and then slowed down. Under the optimal conditions, $\mathrm{Mg}^{2+} \cdot \mathrm{ATP}$ dependent amine release was completed within $15 \mathrm{~min}$. All these results were consistent with those obtained with the direct measurement of released adrenaline (HofFMAN et al., 1976), a fact providing a support for our fluorometric method. 


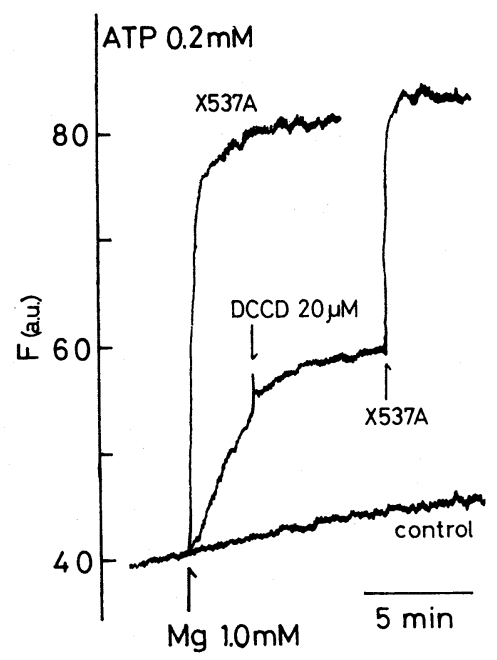

Fig. 11. Effect of DCCD on $\mathrm{Mg}^{2+} \cdot \mathrm{ATP}$-evoked catecholamine release from intact chromaffin granules $(18 \mu \mathrm{g}$ protein $/ \mathrm{ml})$. The media contained $160 \mathrm{~mm} \mathrm{NaCl}$ and $0.2 \mathrm{~mm}$ ATP. The experiment was performed as described in Fig. 9.

The spontaneous catecholamine release (occurring without $\mathrm{Mg}^{2+}$ addition) was quite small and slow, and may result from endogenous $\mathrm{Mg}^{2+}$ of chromaffin granules (around $0.04 \mu \mathrm{mol} / \mathrm{mg}$ of protein, SMITH and WINKLER, 1967). The rate of amine release, expressed as the relative amount of amine released for initial $6 \mathrm{~min}$, apparently increased with increasing $\mathrm{Mg}^{2+}$ concentration up to $1.0 \mathrm{~mm}$, but responded with a substantial decrease to further increase in $\mathrm{Mg}^{2+}$ (Fig. 10 left). Such a dual effect of $\mathrm{Mg}^{2+}$ in the amine release was also noted by HofFMAN et al. (1976).

The linear part of the double-reciprocal plot presented in Fig. 10 right provides $K_{\mathrm{m}}$ of around $0.15 \mathrm{~mm}$ for $\mathrm{Mg}^{2+}$ in range of low concentrations, a value is consistent with that derived from the depolarization response to $\mathrm{Mg}^{2+}$ in the presence of ATP (Fig. 5). Deviation from the linear double-reciprocal plot observed in high $\mathrm{Mg}^{2+}$ range is, as already noted in the previous section, also consistent with the results obtained on the $\mathrm{Mg}^{2+}$. ATP-evoked depolarization. Moreover, DCCD was quite effective in inhibiting the amine release evoked by $\mathrm{Mg}^{2+}$.ATP. As shown in Fig. 11, addition of an ample amount of DCCD immediately stopped liberation of catecholamine activated by prior addition of ATP and $\mathrm{Mg}^{2+}$. All these findings strongly indicate a close correlation of the membrane depolarization with the catecholamine-releasing process.

\section{DISCUSSION}

The main findings of the present study are that the fluorometric method 
with a cyanine dye diS- $\mathrm{C}_{3}-(5)$ was also effective to follow up changes in the membrane potential of isolated chromaffin granules, and that the membrane depolarization proved to occur in the presence of $\mathrm{Mg}^{2+} \cdot \mathrm{ATP}$, the magnitude of which closely paralleled the rate of catecholamine release from the granules.

As shown in Figs. 1 and 3, responses of the fluorescence intensity of diS- $\mathrm{C}_{3}$ (5) in granule suspensions to external cations $\left(\mathrm{K}^{+}, \mathrm{Na}^{+}\right.$and choline $\left.{ }^{+}\right)$and ionophores (valinomycin and gramicidin) were essentially the same as those observed in a number of different preparations ( $c f$. CoHEN and SAlzberG, 1978). Such findings strongly support that fluorometric method of estimating membrane potential changes is also applicable to chromaffin granules. Because of some ambiguities in determining the fluorescence intensity corresponding to zero membrane potential, there remains some doubt as to the absolute value of the membrane potential. The value of $\mathrm{K}^{+}$concentration within the chromaffin cells of adrenal medulla has not yet been measured, but it is expected to be so high as in other cells, probably in the magnitude of $50-100 \mathrm{~mm}$. Allowing some ambiguities, the membrane potential of granules in situ is expected not far from zero from the results presented in Figs. 1 and 3. On the other hand, the membrane potential of granules in low $\mathrm{K}^{+}$media is expected to be some ten $\mathrm{mV}$ inside negative. Pollard et al. (1976), using the distribution of the permeant anion thiocyanate to measure membrane potential of the chromaffin granules, have shown virtually identical value of $-45 \mathrm{mV}$ of granule membrane potential in $0.3 \mathrm{M}$ sucrose, which gives support for the validity of the present fluorometrical measurements of granule membrane potential.

For $\mathrm{K}^{+}$concentrations higher than $20 \mathrm{~mm}$, the relation between $F$ and $\log$ $\left(\mathrm{K}^{+}\right)_{\text {o }}$ was identical with that in the presence of valinomycin (Figs. 1 and 3), which indicates that granule membrane potentials change responding to changes of $\mathrm{K}^{+}$as a potassium electrode at high $\mathrm{K}^{+}$medium. While $\mathrm{K}^{+}$concentrations less than $20 \mathrm{~mm}, F$ in Fig. 3 is not linear with $\log \left(\mathrm{K}^{+}\right)_{0}$, which suggests that granule membrane potentials depend on $\mathrm{Na}^{+}$and $\mathrm{Cl}^{-}$. It is unlikely that chloride played a significant role in this effect because $F$ was almost independent of replacement of $\mathrm{Cl}^{-}$by $\mathrm{SO}_{4}{ }^{2-}$ (Fig. 6). Thus it is suggested from our results that chromaffin granules have membrane potentials which approximate the $\mathrm{K}^{+}$diffusion potential, as is the case of the resting membrane potentials in most nerve cells $\left(P_{\mathrm{K}} \gg P_{\mathrm{Na}}, P_{\mathrm{C} 1}\right)$.

The present study clearly demonstrates that $\mathrm{Mg}^{2+}$. ATP brought about depolarization of the chromaffin granule membrane concomitantly with the catecholamine release therefrom. Our studies on the kinetics of both responses (Figs. 7 and 11) and of inhibitory action of DCCD thereon (Figs. 8 and 12) showed that the magnitude of depolarization paralleled the rate of amine release. It suggests that $\mathrm{Mg}^{2+} \cdot \mathrm{ATP}$ activates a DCCD-sensitive carrier (s) to give rise to electrogenic ion transport accompanied by the amine liberation. DCCD, a potent inhibitor of $\mathrm{Mg}^{2+}$-dependent ATPase associated with 
the chromaffin granule membrane (BASHFORD et al., 1976), was reported to inhibit $\mathrm{H}^{+}$accumulation in submitochondrial vesicles through binding with membrane $\mathrm{H}^{+}$-ATPase (RACKER, 1976). CASEY et al. (1976) provided evidence that only if a permeant anion was present could $\mathrm{Mg}^{2+}$. ATP induce an active $\mathrm{H}^{+}$transport. As shown in Fig. 4, the magnitude of the $\mathrm{Mg}^{2+} \cdot \mathrm{ATP}$-evoked depolarization was decreased with increasing impermeant anion (sulfate) concentration in media. In view of these results, therefore, there is no doubt that a membrane $\mathrm{H}^{+}$-ATPase plays some important role in generating the depolarization response to $\mathrm{Mg}^{2+} \cdot \mathrm{ATP}$. Our indirect estimation of changes in intragranular $\mathrm{K}^{+}$concentration (Fig. 9) suggests a possibility that the ATP-evoked depolarization brings about significant release of internal $\mathrm{K}^{+}$. Furthermore admitting the hypothesis that the membrane $\mathrm{H}^{+}$-ATPase plays a key role in generating the membrane depolarization, it is indeed impossible to attribute the inside positive potentials to increases in $\mathrm{H}^{+}$and $\mathrm{Cl}^{-}$permeability alone, since the intragranular concentrations of $\mathrm{Cl}^{-}$is smaller than that of medium and $\mathrm{pH}_{\mathrm{i}}<$ $\mathrm{pH}_{\mathrm{o}}\left(\mathrm{pH}_{\mathrm{i}}=5.5\right.$ (JOHNSON and SCARPA, 1976b), $\left(\mathrm{Cl}^{-}\right)_{\mathrm{i}}=15-40 \mathrm{~mm}$ (PAZOLES and Pollard, 1978), $\left(\mathrm{Cl}^{-}\right)_{\mathrm{o}}=160 \mathrm{~mm}$ and $\left.\mathrm{pH}_{\mathrm{o}}=6.5\right)$. Thus the depolarization may occur at least through regulation of $\mathrm{H}^{+}$-influx and $\mathrm{K}^{+}$-efflux through granule membrane. Additional evidence for this was given by combination of $\mathrm{K}^{+}$ionophore and uncoupler. In choline $\mathrm{Cl}$ medium, valinomycin induced hyperpolarization of granules (Fig. 1) without release of catecholamine, while further addition of $\mathrm{FCCP}$, which makes granule membrane freely permeable to $\mathrm{H}^{+}$ (JoHNSON and SCARPA, 1976b), caused depolarization and release (data not shown).

Pazoles and Pollard (1978) have investigated in detail the role of $\mathrm{Cl}^{-}$ on $\mathrm{Mg}^{2+}$-ATP-evoked release of catecholamine from isolated chromaffin granules and found that release is a function of $\mathrm{Cl}^{-}$concentration. This is fundamentally compatible with the present result that the magnitude of depolarization was dependent on $\mathrm{Cl}^{-}$(Fig. 6).

The time courses of depolarization and catecholamine release was quite different; the former was rapid, completed within $1 \mathrm{~min}$ and sustained stable over $10 \mathrm{~min}$, while the latter was a slow process lasting over $15 \mathrm{~min}$ (Figs. 2, 9 and 10). These results suggest that $\mathrm{Mg}^{2+} \cdot$ ATP induced depolarization of granules may actually be preconditions for catecholamine release therefrom. The physiological significance of depolarization of granules is not fully elucidated, but it was suggested that depolarization promotes the transport of $\mathrm{K}^{+}, \mathrm{H}^{+}$ and $\mathrm{Cl}^{-}$across the granule membrane to result in release of catecholamine.

Concerning the mechanism of $\mathrm{H}^{+}$transport-linked catecholamine release evoked by $\mathrm{Mg}^{2+} \cdot \mathrm{ATP}$, only a speculation is possible at the present stage of the investigations. Chromaffin granules contain a very high amount of catecholamines and ATP (HILlarP, 1958), and a storage complex of the amines, ATP and $\mathrm{Mg}$ has been postulated (for review see WINKLER and SMITH, 1975). Indeed, 
a recent NMR study suggested the ionic bonds between positively charged $\mathrm{N}$ of adrenaline and the negatively charged phosphates of nucleotides (DANIELS et al., 1978). Thus it is not so unlikely that ATP-driven $\mathrm{H}^{+}$influx possibly modifies such an ionic bond to liberate the amines, resulting in passive efflux of the amines and ATP out of the granules. The rapid catecholamine release from the chromaffin granules observed under external pH lower than 6.0 (HILLARP and NILSON, 1954) appears to support such a speculation.

It is insufficient to assign a physiological role at cellular level to the present results, but there is an attractive hypothesis concerning the role of granule $\mathrm{Mg}^{2+}$. ATPase on secretory process through exocytosis (PAZOLES and Pollard, 1978). Recently, BAKER and KNIGHT (1978) have demonstrated that ATP is necessary for release of catecholamine through exocytosis in adrenal medulla cells. We feel that granule ATPase is one of the main factors which regulate the actual mechanism of release from cells, but further work is necessary to see whether granule ATPase is operating during release in vivo.

The data are taken from a thesis submitted by M.O. to Kyoto University in partial fulfillment of requirement for a M.D. degree. The work was partly supported by Grants 377037 from the Ministry of Education, Science and Culture of Japan.

\section{REFERENCES}

ANTON, A.H. and SAYRE, D.F. (1962) A study of the factors affecting the aluminum oxide trihydroxyindole procedure for the analysis of catecholamines. J.Pharmacol. Exp. Ther., 138: 360-375.

BAKER, P.F. and KNIGHT, D.E. (1978) Calcium-dependent exocytosis in bovine adrenal medullary cells with leaky plasma membranes. Nature, 276: 620-622.

BASHFORD, C.L., CASEY, R.P., RADDA, G.K., and Ritchie, G.A. (1976) Energy-coupling in adrenal chromaffin granules. Neuroscience, 1: 399-412.

CAseY, R.P., NJus, D., RAdDA, G.D., and SeHR, P.A. (1976) Adenosine triphosphate-evoked catecholamine release in chromaffin granules. Biochem. J., 158: 583-588.

CASEY, R.P., NJus, D., RADDA, G.K., and SeHR, P.A. (1977) Active proton uptake by chromaffin granules: Observation by amine distribution and phosphorus-31 nuclear magnetic resonance techniques. Biochemistry, 16: 972-977.

Cohen, L.B. and SAlZBreg, B.M. (1978) Optical measurement of membrane potential. Rev. Physiol. Biochem. Pharmacol., 83: 35-88.

Daniels, A. J., Williams, R. J.P., and Wright, P. E. (1978) The character of the stored molecules in chromaffin granules of the adrenal medulla: A nuclear magnetic resonance study. Neuroscience, 3: 573-585.

Hillarp, N.A. (1958) Adenosine phosphates and inorganic phosphate in the adrenaline and noradrenaline containing granules of the adrenal medulla. Acta Physiol. Scand., 42: 321-332.

HillaRP, N.A. and NiLSON, R. (1954) The structure of adrenaline and noradrenaline containing granules in the adrenal medullary cells with reference to the storage and release of the sympathomimetic amines. Acta Physiol. Scand., (Suppl. 113), 31: 79-107.

Hoffman, P.G., Zinder, O., Bonner, W.M., and Pollard, H.B. (1976) Role of ATP and $\beta$ - $\gamma$-Iminoadenosinetriphosphate in the stimulation of epinephrine and protein release from isolated adrenal secretory vesicles. Arch. Biochem. Biophys., 176: 375-388. 
JOHNSON, R.G. and SCARPA, A. (1974) Catecholamine equilibration gradients of isolated chromaffin vesicles induced by the ionophore X-537A. FEBS Lett., 47: 117-121.

JoHnson, R.G. and SCARPA, A. (1976a) Internal pH of isolated chromaffin granules. J. Biol. Chem., 251 : 2189-2191.

Johnson, R.G. and SCARPA, A. (1976b) Ion permeability of isolated chromaffin granules. J. Gen. Physiol., 68: 601-631.

Kitabgi, J.D. and Perlman, R.L. (1975) The stimulation of catecholamine release from chromaffin granules by valinomycin. Mol. Pharmacol., 11: 745-750.

Lowry, O.H., Rosebrough, N.J., FArR, A.L., and Randall, R.J. (1951) Protein measurement with the Folin phenol reagent. J. Biol. Chem., 193: 265-275.

Pazoles, C.J. and Pollard, H.B. (1978) Evidence for stimulation of anion transport in ATPevoked transmitter release from isolated secretory vesicles. J. Biol. Chem., 253: 3962-3969.

Podleski, T. and Changeaux, J.P. (1969) Effects associated with permeability changes caused by gramicidin A in electroplax membrane. Nature, 221: 541-545.

Pollard, H.B., Zinder, O., Hoffman, P.G., and Nikodejevic, O. (1976) Regulation of the transmembrane potential of isolated chromaffin granules by ATP, ATP analogues, and external pH. J. Biol. Chem., 251: 4544-4550.

RACKER, E. (1976) A New Look at Mechanisms in Bioenergetics, Academic Press, New York.

SMith, A.D. and WinkLer, H. (1967) A simple method for the separation of adrenal chromaffin granules on a large scale. Biochem. J., 103: 480-482.

Steffen, H., DA Prada, M., and Pletscher, A. (1974) Fluorescence properties of catecholamines in isolated storage organelles of adrenal medulla. Biochim. Biophys. Acta, 338: 561-571.

TAUGNER, G. (1972) The effects of univalent anions on catecholamine fluxes and adenosine triphosphatase activity in storage vesicles from the adrenal medulla. Biochem. J., 130: 969-973.

WinkLER, H. and SMITH, A. D. (1975) The chromaffin granule and the storage of catecholamines. In: Handbook of Physiology, Vol. 6, American Physiol. Soc., Bethesda, p. 231. 